\title{
Teaching Feelings on Textile Enterprises Investigation
}

\author{
Yi Liu ${ }^{1, a^{*}}$ \\ ${ }^{1}$ School of Information Engineering, Beijing Institute of Fashion Techology, China, 100029. \\ amableliuyi@163.com
}

Keywords: textile enterprise; teaching; interdiscipline; environmental protection

\begin{abstract}
Paper presents the investigation on different textile enterprises. The investigation focuses on working environment, enterprises operating features, enterprise culture. Thoughts and analisis on characteristics of different jobs, environmental protection idea and interdiscipline teaching are mainly discussed based on the textile enterprises investigation.

In order to combining teaching with textile industry, it is very important way to do on-the-spot investigation. From the investigation, teaching effect can be promoted and teacher can also benefit from it. The enterprises concerned in the paper are different styles and have different features. Some enterprises' business is mainly on design, some is mainly on manufacturing and some is mainly oriented to high level clients. A professional textile market is also included in the investigation. As teachers working in a textile institute, we have been benefit from the investigation, and some thoughts are summarized as followed.
\end{abstract}

\section{Always be optimistic about differences between positions and working environments}

Without experiencing a variety of working environment as I started my teaching career in college after graduating, I was highly astonished to learn how different between the running process of enterprise and the running process of college during this practical training. Moreover, the huge difference between different positions directly lead to totally different working environments. With open and comfort space, most of high-level clothing firms always decorated with arty style. While for some clothing producing firms, employees are working in the factory without any air conditioner even in hot summers. However, the employee can still enjoy his job with lovely music. Robotics are widely used in some enterprises for those in a high level of automatic usage. For example, robotic arms operating by specific programming command. At the same time, some workers are asked to work on simple things, like remove thrums from clothing manually. Although with such big difference in working environments as different positions, we can still always be optimistic about our work and enjoy the work. It is also applicable in teaching area that the results tend to beyond our expectation when we are optimistic about our teaching.

\section{Always keep environmental protection involved in teaching}

During this practical training, it is found that many of producing enterprises are keep aware of environmental protection, they spent a huge amount of money on deal with the sewage. For some designing enterprises, they focus on using environmental materials and maximise the usage of natural resources to advocate environmental protection. As a traditional industry, textile industry is competitively in China with highly international dependency and it is labor intensive with comparing advantages. For past years, textile industry contribute extremely to the rapid economic development of China, thus the awareness of environmental protection of these textile enterprises are affecting our environment condition to some degree. 
Currently, many enterprises are still paying less attention to environmental protection in China, but we can already get the feeling that Chinese clothing producing enterprises are cultivating their concept of environment protection gradually by their positive attitude of environment. Regarding teaching area, students could also improve their understanding of environmental protection if we always keep this concept involved in our daily teaching. No matter of the subject, the concept of environmental protection is able to conveyed by using different ways of expression according to the subject. Specifically, the considering of reduce the radiation of electromagnetism during the teaching of electronic and considering of the natural safety of material during the teaching of chemical, taking the producing process into considering during the designing and so on.

China is in the number one in clothing export, but for long time the products made in China is regarded as low-end products. In order to promote the competitive power of Chinese textile enterprises, advanced technologies and creation should be taken as the keynotes. Textile enterprises can do some scientific cooperation with professional universities, which is an available way to promote the textile enterprises.

\section{Interdiscipline Learning}

In textile enterprises on-the-spot investigation, it can be deeply felt that many different majors professional employees are needed in a professional industry. For example, in a textile manufacturing enterprise, the company require staff majored in fashion design, chemical material, mechanics control, electrical control and other professional staff. When different majored staff make a cooperation, they can't make a good communication if the they can't understand the professional technology each other. So inter discipline learning is very important for university students.

Many teachers have taken part in the the practical on-the-spot investigation. These teachers work in many different majors including arts, chemical materials, electronics engineering, computer science and mechanics engineering. They are good at in their own majors. The teachers all can see the technology related with their own majors. The teachers who major in chemical materials paid more attention on clothing materials. The teachers who major in arts paid more focus on fashion trend, and teachers who major in electronics and computer engineering paid more interest on automation and information application. When teacher discussed together, many creative thoughts have been encouraged. These different majored teachers communicated by presenting different opinions and ideas, they learnt from each other and these discussion can also inspire all the teacher to do more deeper thinking in their own professional fields.

With the developing of science and technology, nowadays the scientific research is in knowledge fusion and interdisciplinary. Interdiscipline is an vital process in high education and cultivation .The rapidly developing of latest advanced technologies encourage many challenges, which is beneficial for personnel training and scientific research group to do interdisciplinary cooperation. Interdisciline can play an important, advanced and supportable role on traditional technologies. It can also improve the scientific research and excavate the potentiality. Besides, communications in many different professional fields can inspire teachers and researchers to construct interdisciplinary knowledge structure and diversification. These can not only enhance the scientific research lever, but also strengthen students work ability, and the students with disciplinary ability will have stronger competitive power in the future.

Generally speaking, teachers working in universities should think highly of putting interdiscipline learning into teaching. The combination can be completed in different aspect, such as 
teaching system, curriculum system. In some open project, teachers can make some interdiscipline topic to encourage students to capture knowledge in different fields, which also demand teachers to learn more professional technology besides own majors.

\section{Conclusion}

In summary, some practical on-the-spot investigation is necessary and important especially for teachers who have never work in enterprises. By textile enterprises on-the-spot investigation, teachers in universities not only can combing teaching with requirement from nowadays industries, but also learn from different enterprises cultures. Advanced teaching ideas and methods can be inspired for teachers to improve education effect.

\section{Acknowledgments}

This work is supported by General program of science and technology development project of Beijing Municipal Education Commission (KM201510012005), Beijing College Student Research Training Program (2015) , Beijing Institute of Fashion Technology Teaching reform and innovation team project ( JGTD-1404), Funding Project for Academic Human Resources Development in Institutions of Higher Learning Under the Jurisdiction of Beijing Municipality, PHR(IHLB) of Innovative Research Team PTTBIFT_TD_002, and Project of Beijing Institute of Fashion Technology Specialty construction(RCPY20150024).

\section{References}

[1]. XU Chaorui, The Problems of Internal Control in College Logistics Enterprises and The Countermeasures, Journal of Henan Textile College[J], , Vol.17 No.2(2005)

[2]. Wang Hongmei, Study and Practie of interdisciplinary Practical and innovative educational platform, Experimental Technology and Management[J], Vol.31 No.11(2014)

[3]. LI Jianxin, Computing science and promoting the development of multi discipline in big data Era, Computer Education[J], Jan.2014

[4]. Exploring the Interdisciplinary Development Path in Collaborative

[5]. YOU Shibing, HUI Yuan, Cui Yawen, Innovation of Higher Educational Institutions, Educational Research[J], No.4(2014)

[6]. ZHENG Xiaoying, Interdisciplinary Developing :Important Contents of Flourishing Philosophy and Social Science, Journal of Peking University(Philosophy and Social Sciences) [J], Vol.44, No .3(2007)

[7]. WANG Mhua, Undergraduate innovative talents cross disciplinary mechanism innovation and system reform, Journal of Southwest University (Social Science Edition), Vol.41No.2(2015) 